\section{Aleksandra Ubertowska}

Uniwersytet Gdański

\title{
Fałda i queer. Natura jako scena homoerotyczna ${ }^{1}$
}

\begin{abstract}
The Fold and Queer: Nature as a Homoerotic Scene

The aim of the text is to examine how the homosexual experience connected with natural spaces such as a beach, park, or dessert, is reflected in diaries and novels by T.E. Lawrence, Witold Gombrowicz, and Michał Witkowski. The author comes to the conclusion that liminal spaces undermine the binaries "nature/culture," "norm/anomie," and "primordial/fabricated." In these works, nature defined as "queerness" (the notion coined by C. Mortimer-Sandilands) seems to play the role of a counter-narrative of modern culture, establishing a different order of moral values and a new, extended (non-anthropocentric) subjectivity that connects species within a set of interactions between plants, water, sand, and climate factors.
\end{abstract}

Słowa kluczowe: queer theory, ekokrytyka, pogranicza, natura/kultura

Keywords: queer theory, ecocriticism, borderlands, nature/culture

1 Artykuł powstał $\mathrm{w}$ ramach realizacji projektu badawczego, finansowanego przez Narodowy Program Rozwoju Humanistyki (2016-2019) pt. „Ekopoetyki historycznych katastrof i konfliktów w literaturze polskiej XX i XXI wieku. Perspektywa porównawcza” (nr 2aH 15005683). 
Formuły filozoficzne i ekokrytyczne odwołujące się do kategorii „natury” istnieją w historii homoerotyczności na różnych prawach, lokowane są w rozmaitych kontekstach znaczeniowych. Na ogół stanowiły one komponent retoryki stygmatyzującej, podtrzymującej przeświadczenie, że homoseksualizm jest „anomalią” jako zespół zachowań niezgodnych z „prawami natury”. Celem takich polityk było wykluczenie osób o orientacji nieheteronormatywnej z ram społecznych, przekształcenie ich w symbolicznego ,innego”, ,wyrzutka", nosiciela antywartości ${ }^{2}$. Subkultury gejowskie często jednak wykorzystywały motywy pastoralne, a także gatunki i konwencje literatury środowiskowej, destabilizując przypisane im znaczenia i utrwalone algorytmy ich użycia. Myśl tkwiąca u podstaw niniejszego artykułu zakłada, że obszar zagadnień z pogranicza ekokrytyki i queer studies zasługuje na wnikliwą analizę, zwłaszcza z perspektywy najnowszych studiów środowiskowych, akcentujących procesy wytwarzania podmiotu w zderzeniu z krajobrazami ryzyka oraz instytucjami władzy symbolicznej ${ }^{3}$. Pomocna w rozwinięciu tego konceptu okaże się Deleuzjańska figura fałdy, którą autor Tysiaca plateau wypracowuje na marginesie swoich rozważań nad filozofią Leibniza i estetyką baroku4. Fałda (a raczej „fałdowanie”, bo procesualność tej figury wydaje się istotna) jest niejako trzecią kategorią, wypowiadającą stan po zniesieniu binaryzmów (płciowych, epistemologicznych, językowych). To - nazywając rzecz inaczej - uwewnętrznienie zewnętrza, Heideggerowsko-Derridiańska różnica, która nieustannie zwija się i rozwija, wyrażając sprzeczność i zarazem jedność „monady jako metafizycznej zasady życia i nieredukowalnej zewnętrzności materii”’ . W koncepcji fałdy szczególnie wartościowe wydały mi się: jej elastyczność, zawarta w niej sugestia materialności (a zarazem organicznej witalności), a także opór, jaki stawia ona dyskursywizacji. Nie bez znaczenia pozostaje także fakt, że figura ta posiada swój wykładnik, by tak rzec, kampowy - wizualno-intelektualne „przegięcie”. Dlatego też posłuży mi ona jako kategoria z zakresu humanistyki środowiskowej, obejmująca przestrzenie graniczne, wiążące w ruchomym splocie sfery natury i kultury, miasta i „dzikości” bytów nie-ludzkich. W stworzonej tu roboczo kategorii „liminalnych obszarów natury” mieściłyby się takie typy przestrzeni, jak plaża, miejskie parki, pustynia zamieszkała przez nomadów i rzeka żeglugowa, wdzierająca się w przestrzeń egzotycznego interioru.

2 Por. D. Boyarin, Homophobia and the Postcoloniality of the „Jewish Science” [w:] Queer Theory and the Jewish Question, eds. D. Boyarin, D. Itzkovitz, A. Pellegrini, New York 2003, s. 170-175.

3 W swoim artykule będę się poruszała w kręgu konceptów wprowadzonych przez ekokrytyków trzeciej i czwartej fali, tak jak ją charakteryzuje Hubert Zapf we wprowadzeniu do wydanej przez siebie antologii ekokrytyki. Zob. H. Zapf, Introduction [w:] Handbook of Ecocriticism and Cultural Ecology, ed. H. Zapf, Berlin-Boston 2016.

${ }^{4}$ G. Deleuze, Fałda. Leibniz a barok, przeł. M. Janik, S. Królak, Warszawa 2014.

5 Ibidem, s. 34. 
Owe „zakładki”, fałdy naturokultury będą tu rozpatrywane jako sceny inicjacji i przygód homoerotycznych (i, szerzej, queerowych). Są one spowinowacone z tego typu doświadczeniem poprzez właściwą im nieprzynależność do ustabilizowanych porządków, zmieszanie ontologicznych właściwości, dziwność, wreszcie siłę subwersywnego oddziaływania na jednoznaczne podziały i granice. Eksplorowanie obszaru wspólnego dla ekologii i queer studies, choć nie ma długiej i ustabilizowanej tradycji, ustanowiło osobny nurt badań w zakresie ekokrytyki, rozwijający swoisty przeciwdyskurs wobec mainstreamowych narracji queerowych. Większość kulturowych zapisów (krypto)homoerotycznych sytuowana jest bowiem w scenerii mieszczańskich i arystokratycznych salonów, a za tło ma nerwowy rytm wczesnokapitalistycznych miast. Opisywanie tropów rustykalnych w literaturze i kulturze gejowskiej podważa zatem powszechne przekonanie głoszące, że homoseksualizm jest produktem wyrafinowanych i dekadenckich kultur miejskich, zjawiskiem z gruntu metropolitalnym. Tymczasem nie jest to do końca prawdą - antyheteronormatywność często splatała się z antyurbanizmem, jak dowodzą prace Scotta Herringa ${ }^{6}$, który badał zjawisko przenoszenia się na wieś subkultur gejowskich i oddziaływanie na lokalne społeczności takich inicjatyw, jak pismo „Rural Fairy Digest" czy działającej w stanie Oregon głośnej lesbijskiej komuny Womenshare Collective. Pozostaje wreszcie literatura - trzeba wspomnieć o sile perswazyjnej znakomitych powieści Annie Proulx Tajemnica Brokeback Mountain i Drwale, która lokuje historie homoerotycznych romansów w scenerii dzikiej przyrody. Najwybitniejsza przedstawicielka queerowej ekokrytyki, Catriona Mortimer-Sandilands, podjęła udaną próbę odzyskania zapoznanych rustykalnych tropów w historii kultury nieheteronormatywnej, przypominając o pastoralnych tradycjach w literaturze, sięgających od pasterskich idylli Teokryta po modernistyczną poezję Walta Whitmana i prozę Henry'ego Davida Thoreau, utworach z kanonu literatur Zachodu, zawierających wyraźne ślady queero$w^{7}$. Mortimer-Sandilands przywołuje również wyniki badań znanego seksuologa Alfreda Kinseya, które dowodzą, że w wieku XIX aktywność homoerotyczna występowała częściej na mitycznym „dzikim Zachodzie”, w typowo homospołecznych wspólnotach kowbojów, drwali, farmerów, niż w miastach wschodniego i zachodniego Wybrzeża. W ten sposób dokonało się w teorii queer „odczarowanie” środowiska przyrody dla kultury gejowskiej, uwolnie-

6 Zob. S. Herring, Another Country: Queer Anti-Urbanism, New York-London 2010.

7 C. Mortimer-Sandilands, Unnatural Passions? Notes toward a Queer Ecology, „InVisible Culture: An Electronic Journal for Visual Culture" 2005, is. 9, http://ivc.lib.rochester.edu/unnatural-passions-notes-toward-a-queer-ecology/ [dostęp: 3.07.2018]. Zob. także C. Mortimer-Sandilands, Queer Life? Ecocriticism after the Fire [w:] The Oxford Handbook of Ecocriticism, ed. G. Garrard, Oxford 2014, s. 305-319. 
nie jej od ideologicznych, wiktoriańskich konotacji, określających homoerotyzm jako formę miejskiej dekadencji, sprzeczną z ,naturalnymi” dyspozycjami seksualnymi.

$\mathrm{Z}$ wielu wątków, które wyłaniają się na przecięciu ekokrytyki i queer studies, Mortimer-Sandilands wybiera tropy foucaultowskie, rozpatrując naturę jako przestrzeń, w której rozgrywane są społeczne relacje w obrębie seksualności. Badaczka ta $\mathrm{z}$ jednej strony definiuje nature jako obszar, który „organizuje siły władzy, a zarazem jest przez nie organizowany" ${ }^{8}$, z drugiej zaś postrzega ją jako miejsce oporu, w którym queerowa wrażliwość ekologiczna może ujawnić się jako antysystemowa i subwersywna. W tym przypadku manifestowanie queerowej podmiotowości byłoby równoznaczne $\mathrm{z}$,wyrwaniem natury z patriarchalnego i zarazem kapitalistycznego systemu produkcji i reprodukcji"9), a także z wydobyciem z niej znaczeń emancypacyjnych, wspierających „etosy mniejszościowe” subkultur gejowskich i bytów nie-ludzkich (non-humans).

\section{Pustynia, al-Haul}

Siedem filarów madrości Thomasa Edwarda Lawrence'a ${ }^{10}$ wydaje się $\mathrm{z}$ wielu powodów „książką założycielską” modernistycznej konwencji autobiografii (krypto)homoerotycznej, wykorzystującej elementy natury. Trudno jednak zrazu dopatrzeć się $w$ niej znamion tekstu intymistycznego. Jest ona kronikarskim zapisem kilku wojskowych eskapad, podjętych w latach 1917-1919 pomiędzy uedem Diraa i Akabą, w których Lawrence jako oficer wywiadu towarzyszył arabskim oddziałom księcia Fajsala, sojusznika Anglików w wojnie z armią turecką. Kronikę poprzedza rozdział antropologiczno-historyczny, zawierający skrót nowoczesnej historii narodów Bliskiego Wschodu oraz imperium osmańskiego. Rzecz jasna, po lekturze Orientalizmu Edwarda Saida (w którym angielski autor jest uosobieniem dwuznacznej figury „białego orientalisty") ${ }^{11}$ nie sposób czytać Lawrence'a, uchylając wiedzę o istnieniu kolonialnej ramy epistemologicznej, modyfikującej obraz kultur północnoafrykańskich, jednak warto pamiętać o tym, że sam Said sytuuje Lawrence'a po stronie narratorów opowieści orientalizujących o tożsamości tragicznie rozdartej, po części sympatyzujących z aspiracjami ludności natywnej. Krążący w tekście motyw ,rebelii” powinien zatem zostać potraktowany jako sygnatu-

8 C. Mortimer-Sandilands, Unnatural Passions?...

9 Ibidem.

10 T.E. Lawrence, Siedem filarów mądrości, przeł. J. Schwakopf, t. I-II, Warszawa 1971.

11 E. Said, Styl, wiedza specjalistyczna, wizja. Globalność orientalizmu [w:] idem, Orientalizm, przeł. M. Wyrwas-Wiśniewska, Poznań 2005, s. 331-341. 
ra autorskich intencji - sam Lawrence jest bowiem rebeliantem podwójnym, zarówno w sferze symbolicznej ekonomii dyskursu kolonialnego, jak i w odniesieniu do porządku libidalnego. Centralne pod wieloma względami wydają się w Siedmiu filarach mądrości relacje łączące ,ja” narratora z pustynią, przestrzenią środowiskową, która pełni w opowieści wielorakie funkcje: od użytkowych po symboliczne. Relacje te mają charakter dynamiczny, zmienny, zawiły, znacznie wykraczający poza binarną opozycję sprawczego ludzkiego podmiotu i pasywnego tła. Pustynia jest tu właśnie ekologiczną fałdą, jawi się jako organiczne, nieludzkie, trudne do okiełznania środowisko, które jest jednak pokryte siecią oaz, osad beduinów, archaicznych studni, szlaków, znanych jedynie tubylcom.

Przedziwna jest „faktura” tej książki, z charakterystyczną dla niej, nienaturalnie zagęszczoną warstwą zdarzeniową, pełną opisów dramatycznych potyczek, zasadzek, wreszcie niebezpiecznych przepraw przez pustynne rejony. Atut, jaki stwarza formuła kroniki, został tu wykorzystany do maksimum, do tego stopnia, że przekształca się ona w swoisty metadokument $\mathrm{z}$ nadbudowanym nad nim dyskursem autoanalitycznym. Wartością, która przynajmniej prowizorycznie porządkuje chaos zdarzeniowy i przestrzenny, wydaje się oscylacja podmiotu, próba ustabilizowania się ,ja” w figurze rozszczepienia, niemożliwej do przezwyciężenia podwójności. Lawrence opisuje siebie jako „człowieka, który patrzył na świat przez podwójną zasłonę: dwóch konwencji obyczajowych, dwóch systemów wychowawczych i dwóch środowisk"12, ale również jako podmiot, który jest wynikiem ekskluzji, wyrzucenia ,poza” (istnieje niejako w prześwicie pomiędzy ,już nie" angielskości i ,jeszcze nie" tożsamości arabskiej). W rezultacie próba osadzenia podmiotu w figurze podwójności lokuje go w pustce, której ekwiwalentem okazuje się pustynia. Pustynia jest w Siedmiu filarach mądrości dominującym aktantem, środowiskiem wszechobecnym, a jednocześnie proteuszowo zmiennym, jawiącym się w wielu formach: jako pasmo wydm, obszar pokryty żwirem, kamieniami, jako dawno wyschnięte koryto rzeki, wreszcie jako wydająca głuche odgłosy absolutna pustka, al-Haul, której przebycie przez człowieka wydaje się prawie niemożliwe.

A kraina ta jest tak pusta, że beduini z Fadżr, jej właściciele, nazwali ją al-Haul. W ciągu całego dnia nie spotkaliśmy śladu życia: ani jednej gazeli, ani jaszczurek, ani szczurzych dziur, ani nawet ptaków. W tej bezmiernej przestrzeni czuliśmy się jak pyłki i mimo szybkiej jazdy ogarniało nas nieodparte wrażenie, że stoimy w miejscu, daremnie tracąc siły. Jedynymi dźwiękami były głuche echa, podobne do odgłosów, jakie słyszy się, idąc po kamiennych płytach ułożonych nad podziemnymi korytarzami, a wywołane grzechotaniem zmurszałych płyt pod nogami wielbłądów, oraz cichy, lecz przenikliwy szept piasku, zwiewanego przez gorący wiatr na zachód wzdłuż wydrążonych przez erozję skał piaskowcowych, którym

12 T.E. Lawrence, Siedem..., t. I, s. 29. 
zagięte do wewnątrz wierzchołki nadawały wygląd pomarańczowych skórek. Wiatr zapierał dech, dysząc tak piekielnym żarem, jakiego czasem doświadcza się w Egipcie w okresie hamsinu ${ }^{13}$.

Rytm kronikarsko-militarnych zapisków podporządkowany jest - na co zwraca uwagę w swojej arcyciekawej interpretacji Siedmiu filarów mądrości Gilles Deleuze ${ }^{14}$ - „subiektywnej dyspozycji” narratora, zmierzającej do zniszczenia ,ja”, rozbicia, rozpylenia podmiotu, który roztapia się w pustynnym środowisku Arabii. Narrator wyraźnie fetyszyzuje pustkę, którą wypełnia wprawdzie natura, jednak nadal figuralizowana jako negatyw (,wiatr, który nie ma smaku”, ,apatyczny wiatr pustynny”, „natura - to, co powstało bez udziału ludzi"). Staranne budowanie scenerii, zdominowanej przez formy deprywatywne ma, jak się zdaje, swoje głębokie uzasadnienie - tylko w takim bowiem, niemal transparentnym krajobrazie możliwe okaże się osadzenie znaków kodujących homoseksualizm. Wszak, jak twierdzą teoretycy intymistyki, pasmem podmiotowości, w którym może ujawnić się homoerotyzm, jest selfless subject ${ }^{15}$, podmiot bez właściwości, podmiot wydrążony (z oznak przynależności do większościowego kodu symbolicznego, budującego ,ja”). Tożsamość seksualna narratora Siedmiu filarów madrości może zatem wyrazić się dwojako: jej zapis przybiera formę kryptotekstu (taki status przysługuje tajemniczemu erotykowi „dla S.A.”w introdukcji książki ${ }^{16}$ ), albo też jest on projektowany na ekran obcej, egzotycznej kultury. Rozwinięciem tej drugiej możliwości wydaje się snucie przez Lawrence'a swobodnych, nieocenzurowanych kulturowo opowieści o romansach i związkach męsko-męskich młodych chłopców Faridża i Dauda, Abdullaha i szejka Aliego.

Powstaje wrażenie, że homoseksualna obyczajowość może się w pełni zrealizować jedynie w naturze jako ,zewnętrzu” kultury, a właściwie w fałdzie, w której kultura funkcjonuje jako znikliwy odcisk, negatyw unieważnionej normy. Narracja biocentryczna przejmuje do pewnego stopnia dynamikę i właściwości homoerotycznej opowieści: opis podróży do Akaby wypełnia niemal erotyczny rytm zmiennych pejzaży, falujacce linie piaszczystych diun odwzorowują niejako senną aurę miłosnego zbliżenia. Co znamienne, Foucaultowska opozycja homoerotycznego ,sekretu i wyznania" ${ }^{17}$, sprawdzająca się w opisie obyczajowości wiktoriańskiej, traci rację bytu w odniesieniu do

13 Ibidem, s. 315.

14 G. Deleuze, Hańba i chwała T.E. Lawrence'a [w:] idem, Krytyka i klinika, przeł. B. Banasiak, P. Pieniążek, Łódź 2016.

15 Por. B. Loftus, The Speaking Silence: The Strategies and Structures of Queer Autobiography, „College Literature” 1997, vol. 24, nr 1, s. 28-44.

16 Jak zakładają biografowie Lawrence'a, adresatem tej dedykacji był szejk Achmed, „Dahum”. Por. R. Norton, The Gay Love Letters of Lawrence of Arabia, http://rictornorton. co.uk/lawrence.htm [dostęp: 15.07.2018].

17 M. Foucault, Historia seksualności, przeł. B. Banasiak, T. Komendant, K. Matuszewski, wstęp T. Komendant, Warszawa 1995, s. 63-65. 
książki Lawrence'a - w organicznym, ziarnistym środowisku pustyni prawda doświadczenia leży na powierzchni, rozproszona horyzontalnie, w jaskrawym świetle podzwrotnikowego słońca. W świecie zdekonstruowanych norm seksualności nie ma potrzeby skrywania nieprawomyślnych treści i potrzeb libidalnych, są one niejako dane, niczym przedustawna materia (a zatem unieważniają, opisany przez Judith Butler, porządek ,,wtórnej naturalizacji” kulturowo skonstruowanych heteronorm).

Ludzie byli młodzi i silni, a ich gorące ciała i krew domagały się podświadomie swych praw, torturując trzewia dziwnymi pożądaniami. Nędza i niebezpieczeństwo podsycały ten męski żar, spotęgowany najbardziej morderczym klimatem, jaki można sobie wyobrazić. Na pustyni nie było kryjówek, w których moglibyśmy się odizolować, ani grubych, zapewniających dyskrecję ubrań. We wszystkich sprawach mężczyzna z mężczyzną współżyli otwarcie i szczerze ${ }^{18}$.

Jeśli przyłożyć do lektury Siedmiu filarów mądrości klucz homoerotyczny, to w nieco innym świetle objawią się wcześniej odnotowane właściwości tekstu. Poetyka nadmiaru - zdarzeniowego, stylistycznego, leksykalnego - będzie przywodzić na myśl tradycję kampu, eksponującego język sztucznie zagęszczony, konstruktywistyczny, zmysłowy. W relacji Lawrence’a kamp niejako oczyszcza przedpole dla ekspozycji homoseksualności. Właśnie kategoria ekspozycji homoerotycznego libido (ekspozycji w świetle słońca) wydaje się najbardziej adekwatną kategorią opisu Lawrence'owskiej strategii zapisu doświadczeń nieheteronormatywnych.

W tym samym porządku pozwala się usytuować motyw ciała (ciał?), nieustannie wystawianego na działanie warunków klimatycznych: upału, huraganowego wiatru, burz piaskowych, mrozu i śniegu. Ciało jest tu punktem przecięcia wielu dyskursów: kolonialnego, queerowego, ekologicznego. Co znamienne, narrator Siedmiu filarów mądrości nieustannie akcentuje zmysłową, cielesną bliskość ludzkiego podmiotu wobec materialności natury. Lawrence, nawet jeśli pokonuje teren na grzbiecie wielbłądzicy, opisuje powierzchnię gleby tak, jakby dotykał jej bezpośrednio stopami, starając się sprostać ideałowi, jaki na Bliskim Wschodzie ustanowili arabscy chłopcy, którzy potrafią godzinami biec boso po rozgrzanym piasku. Moglibyśmy zatem powiedzieć, że Lawrence'owi przyświeca ekokrytyczna filozofia lepkości/intymności Timothy’ego Mortona ${ }^{19}$, zakładająca zniesienie dystansu na linii człowiek-środowisko. Powierzchnia skóry, choćby na poziomie reprezentacji, przylega do powierzchni świata bytów nie-ludzkich, przekształcając ontologiczną granicę w przepuszczalną membranę wrażeń zmysłowych i poznawczych.

18 T.E. Lawrence, Siedem..., t. I, s. 25.

19 Kategorię lepkości (viscosity) wprowadził przedstawiciel czwartej fali ekokrytyki, Timothy Morton, w książce Hyperobjects: Philosophy and Ecology after the End of the World, Minneapolis 2013. 


\section{Natura jako obszar kulturowej inwersji}

W poszukiwaniu punktów, w których na mapie twórczości Witolda Gombrowicza wyznanie homoerotyczne krzyżuje się z narracją ekokrytyczną, poświęconą opisom egzotycznej, podzwrotnikowej przyrody, nieuchronnie docieramy do tekstów z okresu emigracyjnego: Kronosa i Diariusza Rio Parana, w których do fałdy ekologiczno-homoerotycznej dołącza komponent przestrzennego oddalenia, kulturowej obcości, związanej z kondycją emigranta.

Interesujący z tego punktu widzenia wydaje się zwłaszcza, opublikowany dopiero kilka lat temu, tajny dziennik autora Trans-Atlantyku. W diariuszu tym Gombrowicz w formie wielce prowizorycznej rejestruje wydarzenia codzienne, trywialne: męczącą pracę w Banco Polaco w Buenos Aires, problemy finansowe, kolacje z przyjaciółmi, zapisuje także wczesne, szkicowe wersje powieści i dramatów. Dominują w Kronosie zapiski krótkie, lapidarne, częściowo zaszyfrowane, panuje w nim wrażenie bezładu. Mogłoby się wydawać, że dziennik ten to zbiór „fiszek w intymistycznym archiwum”, które stanowią zaledwie surowy materiał do przetworzenia w literacki dziennik. Taki trop podsuwa przytłaczający, ale i enigmatyczny tytuł diariusza. Kronos był, jak wiadomo, ojcem Zeusa, mityczną postacią, która może być interpretowana jako figura początku, 'arche', ale także obszaru pierwotnych instynktów, które kultura traktuje jako 'tabu', jako przekazy wykluczone z zasobu ustabilizowanych form symbolicznych. Podążając za tą sugestią, powiedzielibyśmy, że Kronos to tekst, który był przed Dziennikiem, to prehistoria literackiego diariusza, a zatem prawdziwy dziennik intymny, nieprzeznaczony do druku, niewystylizowany, w którym można zrekonstruować hipotetyczny ,język nieheteronormatywności”20, gejowskiej „libido”, ukrytej lub nieczytelnej w innych utworach pisarza ${ }^{21}$.

Wrażenie to potęguje nietypowa czasowość dziennika. Zazwyczaj zapiski diarystyczne są nanoszone na oś czasu, mają charakter linearny. W Kronosie istnieją jedynie nieregularne adnotacje, odnoszące się do miesięcy i lat, wydarzenia zaś układają się w „pryzmę”, stertę bezładnych, nawarstwiających się zapisków. Ten eliptyczny zapis skrywa i zarazem odsłania istotne informacje - prawdę o homoerotycznych doświadczeniach pisarza, przygodnych schadzkach w parku Retiro ${ }^{22}$, romansach i fascynacjach, zarówno pisarzami,

20 P.S. Rosół, Genet Gombrowicza. Historia miłosna, Gdańsk 2016, s. 25.

21 Por. bardzo inspirujące uwagi Piotra Sobolczyka na temat pozycji Kronosa jako bardziej autentycznego, wobec zdominowanego przez eskapistyczne estetyki Trans-Atlantyku („,kamp maniczny”) i Dziennika: P. Sobolczyk, Queerowe subwersje: Polska literatura homotekstualna i zmiana spoteczna, Warszawa 2015, s. 149.

22 Na temat symboliki dzielnicy i parku Retiro na symbolicznej mapie Gombrowicza por. J. Margański, Miejsce poza mapa - Retiro [w:] idem, Geografia pragnień. Opowieść o Gombrowiczu, Kraków 2005, s. 136-143. Zapiski z Kronosa jednak podważają frag- 
jak i młodymi mężczyznami z ludu. Nazwa własna „Retiro” - oznaczenie lokalnego miejsca gejowskich schadzek - krąży w tekście, nieustannie powraca jako znak rozpoznawczy libidalnej narracji, ukrytej pod chaotyczną pryzmą pozornie nieznaczących, nieuformowanych literacko zapisków diarystycznych.

Ten rok to rok ,inicjacji”. Wchodzę w Argentynę.

Tracę dawniejsze opory. Przeistaczam się w cygana. [...]

Wzrasta oczarowanie... Z początku to spacery po porcie, Retiro... Odkrywam teren na Corrientes. Chodzę dużo. Ale jeszcze mam duże wymagania - $\mathrm{i}$ ambicje... Po czym przystosowuję się ${ }^{23}$.

W drugim półroczu wzrasta aktywność i chodzę do parku Retiro, który mnie zachwyca, a także w centrum ${ }^{24}$.

Zaczynam na Retiro, sam. Pierwsza połowa miesiąca pod znakiem Aldo, który nie przychodzi na rendez-vous ${ }^{25}$.

Wielkanoc. Alberto, marinero. Retiro. Pobieram dywidendy Fabril i Emeta bardzo spadły. Piątek 7-go Roberto, Retiro, żotnierz ${ }^{26}$.

Właśnie przestrzeń parku - fałdy miasta i natury - okazuje się czynnikiem stabilizującym procesy dynamicznej i chaotycznej semiozy w obrębie tekstu, punktem, który zespala ważne linie doświadczeń. Park - jak poucza ekokryty$\mathrm{ka}$ - łączy sprzeczne funkcje w krajobrazie urbanistycznym ${ }^{27}$. Jest przykładem „sfabrykowanej autentyczności”, natury otamowanej, oswojonej, nie tylko istniejącej jako kulturowy konstrukt, ale wręcz manifestującej ten swój status. Mortimer-Sandilands zwraca uwagę na fakt, że parki miejskie były ważnym obszarem dyscyplinującego kultywowania mieszczańskich cnót, przestrzenią publicznego odgrywania heteronormatywności (w formie starannie celebrowanych rodzinnych i romantycznych spacerów $)^{28}$. Park umiejętnie naturalizuje społeczne konstrukty heteryckiej rodziny, dwóch płci, kulturowej podległości dzieci i kobiet. Zarazem jednak subkultury gejowskie właśnie parki obrały sobie za miejsce schadzek, czyniąc z nich scenę kulturowej inwersji.

W Kronosie park Retiro występuje w takiej właśnie funkcji. Jawi się jako domena tonącej w mroku, nieprzeniknionej roślinności, która sprzeniewierza się mieszczańskiej, „ogrodniczej” kulturze i jako taka stanowi odpowiednią scenerię niepohamowanej ekspresji homoerotycznych pragnień. Zespalają się

menty z Dziennika Gombrowicza, na które powołuje się autor, gdyż tam pisarz wyraźnie bagatelizuje swoje doświadczenia homoerotyczne z okresu pobytu w Argentynie.

23 W. Gombrowicz, Kronos, wstęp R. Gombrowicz, posłowie J. Jarzębski, przyp.

R. Gombrowicz, J. Jarzębski, K. Suchanow, Kraków 2013, s. 83.

24 Ibidem, s. 90.

25 Ibidem, s. 150.

26 Ibidem, s. 253.

27 Por. D. Mazel, American Literary Environmentalism, Athens 2000.

28 C. Mortimer-Sandilands, Unnatural Passions?... 
tu różnorodne aspekty projektu literackiego, jakim jest Kronos - surowa, robocza pre-forma tekstu i zapis prekognitywnych opiłków doświadczeń oraz form bytu, które kultura odrzuca dlatego, że są nie-ludzkie lub mieszczą się poza dominującymi reżimami seksualności.

Istotny wydaje się komponent egzotyki jako nieusuwalny element homoseksualnego wtajemniczenia. Nasuwa się tu analogia do filmu Petera Greenawaya Eisenstein in Guanajuato (polski tytuł: Eisenstein w Meksyku), opowiadającym o odkryciu przez rosyjskiego reżysera swojej homoseksualnej natury. Tak jak u Greenawaya, w przypadku Gombrowicza warunkiem odkrycia swojej tożsamości była radykalna zmiana scenografii, przemieszczenie geograficzne, ale i kulturowe. Można odnieść wrażenie, że w obydwu biografiach inności, ekscentryczności oświetlają się wzajemnie i potęgują swoją moc oddziaływania, aż do porzucenia narzuconych w ojczyźnie tożsamości.

Egzotyka, egzotyczna przyroda jako radykalna inność najpełniej dochodzi do głosu w Diariuszu Rio Parana ${ }^{29}$. Czytany retrospektywnie, filtrowany przez achronologiczną lekturę Kronosa, wydaje się on silnie związany z intensywnymi doznaniami homoerotycznymi z okresu argentyńskiego, choć na pozór brak w nim bezpośrednich do niego odwołan. Zapis trwającej ponad tydzień podróży tworzy w oficjalnym Dzienniku Gombrowicza osobny tekst, napisany kursywą, co nadaje mu szczególny, wyróżniony charakter. Typograficzny chwyt pozbawia doświadczenie podróży realizmu, każe doszukiwać się w nim egzystencjalno-środowiskowej metafory, funkcjonującej na metapoziomie narracji o żegludze. Rzeczywiście, Diariusz Rio Parana to osobliwa relacja z podróży, pozbawiona elementu zdarzeniowego czy przygodowego, zwłaszcza z udziałem ludzi. Postaci podróżników są statyczne, zaledwie naszkicowane, pozbawione sprawczości (agency). Dominuje wrażenie bezczasowości, wolnego rytmu, wyznaczanego przez powtarzającą się frazę „Płyniemy, płyniemy".

Płyniemy deltą Parana. Wody są metalowe, a niebo skłócone, złe - nad Urugwajem chmury rozpuściły włosy i deszczem sięgają ziemi. Żałość.

Woda rośnie, wzbiera, a przed nami chmura zakorkowała horyzont, rzeka rośnie ciemnością, chmura wytycza z siebie zwały ciemności, ciemność paruje z brzegów odległych o kilka kilometrów ${ }^{30}$.

Potencjał zdarzeniowy zostaje $\mathrm{w}$ dzienniku przemieszczony $\mathrm{w}$ sferę natury - narracja składa się z mikrozdarzeń, zachodzących w nurcie rzeki i na jej brzegach, a także na rozpalonym niebie („żółta woda, białawe niebo”). Dynamikę opowieści wytycza zmienność pejzażu, gdy rzeka zwęża się i staje przesmykiem pomiędzy siedmioma jeziorami, usytuowanymi na różnych wysokościach, lub gdy dochodzi do gwałtownego zmieszania wód rzek i oceanu.

29 W. Gombrowicz, Dziennik 1953-1956, red. J. Błoński, Kraków 1986, s. 312-321.

30 Ibidem, s. 313. 
Panuje wrażenie niemal erotycznego roztapiania ludzkiego podmiotu w żywiole natury, zatracania się w egzotycznej inności, która fascynuje i zarazem przeraża autora. Wydaje się bowiem figurą niesamowitego (uncanny), bytu, który nie pozwala się do końca opisać i poznać.

Gombrowicz jako pisarz usiłuje wywikłać się z dylematu niewyrażalności, porzucając niemal całkowicie wzorce narracji antropocentrycznych, tworząc opowieść biomorficzną, naśladującą organiczność żywiołów akwatycznych i bujność, nieokiełznanie podzwrotnikowej przyrody. W Diariuszu Rio Parana nie ma ludzkiego podmiotu, wartościującego otaczający świat, narracja jest rozproszona, składa się z niepowiązanych zdań, tworzących nieregularne pasma. Łączą się w tych sekwencjach narracyjnych obrazy wody, roślin, fantastycznych zwierząt, archetypicznej ciemności, która staje się motywem naczelnym dziennika (i odniesieniem do Jądra ciemności Conrada). W przeciwieństwie do Marlowe'a narrator Diariusza Rio Parana nie kolonizuje wzrokiem obcego świata, nie uczestniczy w jego epistemicznym podboju, przeciwnie - pozwala mu istnieć autonomicznie, co prowadzi często do pochłonięcia ludzkiego ,ja" przez procesy natury.

Nasuwa się tu jako kontekst teoretyczny pojęcie biological queerness, wprowadzone do ekokrytyki przez Mortimer-Sandilands ${ }^{31}$ na określenie nieustannej biogenetycznej wymiany pomiędzy różnymi gatunkami i bytami, która określa istotę życia na ziemi. Rozwój biologiczny, zdaniem amerykańskiej badaczki, dokonuje się poprzez materialne sploty i międzypodmiotowe sensualno-seksualne spotkania (interagential sensual-sexual encounters), znoszące kulturowe binarne opozycje pomiędzy „męskim i żeńskim”, ,seksualną normą i anomalią”, ,przyjemnością i (bolesną) perwersją". Queerowość zyskiwałaby w tym kontekście odmienny, poszerzony sens, by tak rzec, ponadpodmiotowy, światowy. Termin queer użyty w tym kontekście spaja sferę bioform - autonomicznych, niestabilnych ontologicznie, wyłamujących się z wszelkich typologii - z gestem subwersji na poziomie tożsamości, podmiotowości.

\section{Plaża jako scena homoerotycznych opowieści}

W przeciwieństwie do autobiografii Lawrence'a, odwołującej się, przynajmniej częściowo, do utopijnej wiary w istnienie pierwotnej natury jako przestrzeni libidalnej wolności, Lubiewo Michała Witkowskiego za punkt wyjścia obiera odrzucenie antropocentrycznego i zarazem esencjalistycznego obrazu przyrody, która jawi się autorowi jako nieuchronnie skonstruowana, zapośredniczona przez znaki. Zasadą organizującą powieść jest zatem dekonstruowa-

31 C. Mortimer-Sandilands, Queer Life?... 
nie konwencji mimetycznego odwzorowania natury poprzez jej cytowanie, inscenizowanie lub uwikłanie w gry estetyczne.

Uśmiechnął się do mnie i podjechał tym swoim wózkiem. Ja - twarz jak ściana. Wiatr. Oj, tam akurat tego popołudnia przyroda naprawdę podkreślała odczucia bohaterów. Nagle zaczęło wiać i znosić mi włosy na oczy. No i burza mózgu, co robić, jak powstrzymać płacz? ${ }^{32}$

Natura jest tu zaledwie fetyszem realistycznego pisarstwa, zleksykalizowaną figurą stylistyczną, której można używać już jedynie w ramie ściśle określonej modalności - na metapoziomie zjadliwie autoironicznego komentarza. Podobnej dekonstrukcji ulega czasoprzestrzeń powieści i zapisanego w niej doświadczenia; topografie parku, europejskich metropolii, starych mieszkań, plaży wreszcie - wyłaniają się nielinearnie, na mocy przypadkowej logiki wspomnień lub anegdotycznej dygresji, nakładając się na siebie w tekstowym palimpseście.

Przestrzeni plaży przysługuje w powieści Witkowskiego uprzywilejowany status. Została ona przywołana $\mathrm{w}$ tytule, pojawia się również często we fragmentach przerywających tok opowieści, kontrapunktujących przestrzenie wielkomiejskie. Rob Nixon w swoim autobiograficznym eseju Barrier Beach ${ }^{33}$ zwraca uwagę na specyficzny charakter tej topografii natury, która - choć wydaje się enklawą środowiskową, autonomicznym obszarem przyrody $\mathrm{w}$ istocie wchłania skomplikowane stratyfikacje społeczne, procesy historyczne, etniczne i światopoglądowe podziały. Swoje rozważania Nixon ilustruje opisem plaży swojego dzieciństwa na południowoafrykańskim Cape Cod, na której obowiązywała segregacja rasowa, oznaczana tabliczkami („,Tylko dla białych") w języku angielskim i afrikaans. Co znamienne, ta sama plaża po zniesieniu apartheidu przyjęła nazwę „Mandela Beach”. Plaża - przestrzeń środowiskowa, która w tak sensualny sposób kształtuje postawę dziecka wobec natury - okazuje się tu nośnikiem znaczeń historycznych, przechowuje jej zmienną dynamikę.

W powieści Witkowskiego plaża jest podobną fałdą natury, obyczajowości, historii, estetyki, przejmuje odpryski każdego z tych porządków, znamienne dla nich stratyfikacje i rytmy rozwoju. Najistotniejszy wydaje się w powieści podział na plażę jako neutralną strefę relaksu (choć niewątpliwie wiążącą się z nagością oraz aluzjami do seksualności) i na przestrzeń wydm - wakacyjną ,pikietę”, miejsce schadzek „ciot - emerytek”. Ta ostatnia opisywana jest jako domena abiektalnej obyczajowości erotycznej, seksualności orgiastycznej, przygodnej, ale zarazem niezmiernie pociągającej dla bohaterów. Wydmy

32 M. Witkowski, Lubiewo, Kraków 2004, s. 54.

33 R. Nixon, Barrier Beach [w:] The Oxford Handbook of Ecocriticism, ed. G. Garrard, Oxford 2014, s. 560-565. 
wchłaniają procesy historycznych przemian pomiędzy epokami; dynamikę tę wydobywa Lukrecja, mówiąc o diunach, że ,kiedyś (to było) miejsce utajnienia, dzisiaj miejsce ujawnienia".

Ta stratyfikacja spacjalna pokrywa się z podziałem społecznym na ,cywilizowanych gejów” epoki poemancypacyjnej i „,cioty”, weteranów PRL-owskiego podziemia homoerotycznego ${ }^{34}$.

Mówią o sobie w rodzaju męskim. Są z „fazy emancypacyjnej” (my nie, więc granica przebiega przez plażę, jakoś tak na wysokości wymarłego radaru i czerwonej flagi). Chodzą do Scorpio Bar. Walczą o prawo do małżeństwa i adopcji. W ogóle walczą, dążą ${ }^{35}$.

Pozycja narratora Lubiewa jest zmienna, nomadyczna - niczym „duch opowieści” jest on obecny w wielu miejscach i czasach, testuje swój (osłabiony) autorytet w różnych konwencjach estetycznych i narracyjnych. W trakcie rozmów z kosmopolitycznymi gejami z Poznania mówi o sobie, używając formy męskoosobowej, najczęściej jednak - jako Michaśka - utożsamia się z ,„przegiętymi ciotami z marginesu III RP"36. Ta identyfikacja rozciąga się również na symboliczną przestrzeń liminalnej plaży, która jest tu reliktem epoki przedemancypacyjnej ( $m y$, cioty z wydm). Narrator Lubiewa jest więc podmiotem zagubionym, niejako wytrąconym z formy, o jego (performatywnej) tożsamości decyduje wahliwy ruch w systemie znaków - zmiana zaimka osobowego. Podobnie plaża w ogóle nie jest tu odbierana sensualnie, przeciwnie - jawi się jako struktura. Rozpoznanie to wydaje się kluczowe dla zrozumienia statusu plaży i wydm w powieści. Nieprzypadkowo wyprawy na wydmy „cioty” Witkowskiego nazywają „bergowaniem”, wakacyjną subkulturę gejowską zaś - „gejowskim Bergiem”. Te reminiscencje literackie wydają się głęboko przemyślane. Plaża - niczym pejzaż górski w Kosmosie Gombrowicza - jest w Lubiewie sferą znaczącego: domeną porozumiewawczych znaków, subtelnych granic, arbitralnych zakazów i ruchomych binaryzmów semantycznych.

Co najistotniejsze jednak, plaża jest w Lubiewie sceną opowieści. Michaśka, sadowiąc się na kocu, mówi o sobie ,ja jestem od opowieści”, „zaraz opowiem coś o sobie". To właśnie z tej fałdy naturokultury wydobywa się fonocentryczny potok mowy wieloosobowego narratora, który stara się prze-

34 Na pewnym poziomie mamy tu oczywiście do czynienia z grą ze stereotypem ,geja-wyrzutka”, uosabiającego anomie społeczne. Por. J. Kochanowski, Wszyscy jesteśmy odmieńcami. Przyczynki do społecznej teorii queer [w:] Parametry pożądania. Kultura odmieńców wobec homofobii, red. T. Basiuk, D. Ferens, T. Sikora, współpr. M. Lizurej, Kraków 2006, s. 37-49.

35 M. Witkowski, Lubiewo, s. 51.

36 Błażej Warkocki sytuuje Lubiewo (bohaterki, ale i odmianę homopowieści) w kręgu genetowskiej formuły „opowieści o (gejach) upadłych”, w przeciwieństwie do „peryfrastyków” i „normalsów”. Por. B. Warkocki, Mapa odmienności [w:] idem, Homo niewiadomo. Polska proza wobec odmienności, Warszawa 2007, s. 41. 
mawiać w imieniu całej wspólnoty wykluczonych „ciot”, marginesu marginesów nowoczesnego społeczeństwa. Przypomina się zdanie Gertrudy Stein, która mówiła o tym, że prawda homoseksualnego doświadczenia wydobywa się z ,podszewki tekstu” - w homopowieści Witkowskiego najbardziej ambarasująca narracja o życiu osób nieheteronormatywnych wypływa - niczym bezładna gadanina Białoszewskiego, który zostaje zresztą zacytowany w powieści - z „zakładki ontologicznej” miejskiej cywilizacji i skrawka liminalnej natury.

$*$

Niewątpliwie kategorie środowiskowe występują w omawianych tu literackich zapisach doświadczeń homoerotycznych w wielu funkcjach, przede wszystkim jednak jako język wymienny w stosunku do homoseksualnego doświadczenia, którego podmiot nie dysponuje językiem neutralnym, nienacechowanym pejoratywnie, nieobarczonym znakiem kulturowego 'tabu'. Ekopoetyki jako nieantropomorficzne formy wyrazu dysponują większym potencjałem neutralności i zdolności nazywania zjawisk słabo osadzonych w kulturze, marginalizowanych. A zatem estetyczne kategorie biotycznej dziwności, hybrydyczności, egzotyki stały się w analizowanych tu tekstach językiem metonimicznym, opisującym doświadczenie transgresji kulturowych, genderowych, psychicznych.

\section{Bibliografia}

Boyarin D., Homophobia and the Postcoloniality of the „Jewish Science” [w:] Queer Theory and the Jewish Question, eds. D. Boyarin, D. Itzkovitz, A. Pellegrini, New York 2003.

Deleuze G., Fałda. Leibniz a barok, przeł. M. Janik, S. Królak, Warszawa 2014.

Deleuze G., Hańba i chwała T.E. Lawrence'a [w:] idem, Krytyka i klinika, przeł.

B. Banasiak, P. Pieniążek, Łódź 2016.

Foucault M., Historia seksualności, przeł. B. Banasiak, T. Komendant, K. Matuszewski, wstęp T. Komendant, Warszawa 1995.

Gombrowicz W., Dziennik 1953-1956, red. J. Błoński, Kraków 1986.

Gombrowicz W., Kronos, wstęp R. Gombrowicz,posłowie J. Jarzębski, przyp. R. Gombrowicz, J. Jarzębski, K. Suchanow, Kraków 2013.

Herring S., Another Country. Queer Anti-Urbanism, New York-London 2010.

Kochanowski J., Wszyscy jesteśmy odmieńcami. Przyczynki do społecznej historii queer [w:] Parametry pożadania. Kultura odmieńców wobec homofobii, red. T. Basiuk, D. Ferens, T. Sikora, współpr. M. Lizurej, Kraków 2006.

Lawrence T.E., Siedem filarów mądrości, przeł. J. Schwakopf, t. I-II, Warszawa 1971. 
Loftus B., Speaking Silence: The Strategies and Structures of Queer Autobiography, „College Literature” 1997, vol. 24, nr 1.

Margański J., Geografia pragnień. Opowieść o Gombrowiczu, Kraków 2005.

Mazel D., American Literary Environmentalism, Athens 2000.

Mortimer-Sandilands C., Queer Life? Ecocriticism after the Fire [w:] The Oxford Handbook of Ecocriticism, ed. G. Garrard, Oxford 2014.

Mortimer-Sandilands C., Unnatural Passions? Notes toward a Queer Theory, „InVisible Culture: An Electronic Journal for Visual Culture" 2005, is. 9.

Morton T., Hyperobjects: Philosophy and Ecology after the End of the World, Minneapolis 2013.

Nixon R., Barrier Beach [w:] The Oxford Handbook of Ecocriticism, ed. G. Garrard, Oxford 2014.

Norton R., The Gay Love Letters of Lawrence of Arabia, http://rictornorton.co.uk/lawrence.htm [dostęp: 15.07.2018].

Rosół P.S., Genet Gombrowicza. Historia miłosna, Gdańsk 2016.

Said E., Orientalizm, przeł. M. Wyrwas-Wiśniewska, Poznań 2005.

Sobolczyk P., Queerowe subwersje. Polska literatura homotekstualna i zmiana spoteczna, Warszawa 2015.

Warkocki B., Homo niewiadomo. Polska proza wobec odmienności, Warszawa 2007. Witkowski M., Lubiewo, Kraków 2004.

Zapf H., Introduction [w:] Handbook of Ecocriticism and Cultural Theory, ed. H. Zapf, Berlin-Boston 2016. 